\title{
THE MEASUREMENT OF PULMONARY CAPILLARY BLOOD VOLUME AND PULMONARY MEMBRANE DIFFUSING CAPACITY IN NORMAL SUBJECTS; THE EFFECTS OF EXERCISE AND POSITION 1, 2
}

\author{
By BENJAMIN M. LEWIS, TAI-HON LIN, 3 FRANCES E. NOE, 4 AND \\ RICHARD KOMISARUK ${ }^{5}$ \\ (From the Department of Medicine, Wayne State University, and the Department of Medicine, \\ Detroit Receiving Hospital, Detroit, Mich.)
}

(Submitted for publication February 10, 1958; accepted March 6, 1958)

Carbon monoxide combines with oxyhemoglobin at a measurable rather than an infinitely fast rate $(1,2)$. This fact is important when carbon monoxide is used to estimate pulmonary diffusing capacity. If the rate at which this gas crosses the membrane between alveoli and pulmonary capillaries is greater than the rate at which it can react with oxyhemoglobin, carbon monoxide tension will rise in these capillaries and slow further diffusion. Therefore, the diffusing capacity of the lungs for carbon monoxide is dependent not only on the thickness and area of the membrane between alveoli and capillaries, but also on the volume of blood in the capillaries and the rate at which this blood can react with carbon monoxide. Roughton and Forster ( 3 ) have recently shown that pulmonary capillary blood volume and the true diffusing capacity of the pulmonary membrane can be computed from data on the apparent diffusing capacity of the lung for carbon monoxide $\left(\mathrm{DL}_{\mathrm{CO}}\right)$ at different oxygen tensions and in vitro values for the rate of reaction of carbon monoxide with oxyhemoglobin contained in red cells $(\theta) .^{\circ}$ Such

\footnotetext{
1 This work was supported by grants from the Receiving Hospital Research Corporation, The National Institutes of Health (Grant H-2379), and the Michigan Heart Association.

2 This material was presented, in part, before the Midwest Section, American Federation for Clinical Research, Chicago, Illinois, October 31, 1957, and was read by title at the meeting of the Central Society for Clinical Research, Chicago, Illinois, November 1, 1957.

8 Part of this work was performed while a Fellow of the Rands Foundation.

4 Fellow of the Rands Foundation.

5 This work was performed while a Medical Student Fellow of the United States Public Health Service.

- $\theta$ includes both the rate of reaction of $\mathrm{CO}$ with oxyhemoglobin and the rate of diffusion of $\mathrm{CO}$ within the red cell.
}

computations have obvious importance in disease states in which the true diffusing capacity of the pulmonary membrane $\left(D_{\mathbf{M}}\right)$ and the capillary blood volume $\left(V_{\mathbf{C}}\right)$ might vary independently. The present paper presents computations of $V_{\mathbf{C}}$ and $D_{M}$ in 19 normal subjects and the changes produced in $V_{C}$ and $D_{M}$ by exercise and alterations in body position.

\section{METHODS}

A. Principle. The diffusion of carbon monoxide from alveolus to capillary is opposed by the resistance of the membrane between alveolus and capillary and by a resistance made up of both the rate at which $\mathrm{CO}$ combines with oxyhemoglobin and the volume of blood in the capillaries. The total resistance to diffusion then may be likened to two electrical resistances arranged in series. Thus:

Total resistance $=$ membrane resistance + blood resistance.

The apparent diffusing capacity of the lungs for carbon monoxide (DLco) is essentially flow/pressure and thus analogous to an electrical conductance; its reciprocal $\left(1 / \mathrm{DL}_{\mathrm{co}}\right)$, however, is a resistance and represents the total resistance to diffusion. The true diffusing capacity of the pulmonary membrane $\left(D_{x}\right)$, the reaction rate of carbon monoxide with oxyhemoglobin $(\theta)$ and the volume of blood in the capillaries $\left(\mathrm{V}_{\mathrm{c}}\right)$ are also analogous to electrical conductances; their reciprocals express the resistances due to the membrane and to the blood, respectively. Thus, the equation above may be restated symbolically:

$$
1 / D_{\text {LoO }}=1 / D_{M}+1 / \theta \times 1 / V_{C}
$$

A rigorous mathematical derivation of this equation has been given by Roughton and Forster (3).

$\theta$ decreases with increasing $\mathrm{pO}_{2}$ in the capillary blood, and its value at $\mathrm{pO}_{2}$ 's of greater than about $100 \mathrm{~mm} . \mathrm{Hg}$ (where there is no appreciable reduced hemoglobin) is known from in vitro data (2). Dlco may be measured at several different levels of capillary $\mathrm{pO}_{2}$, corresponding to several different values of $\theta$. If the reciprocals of 


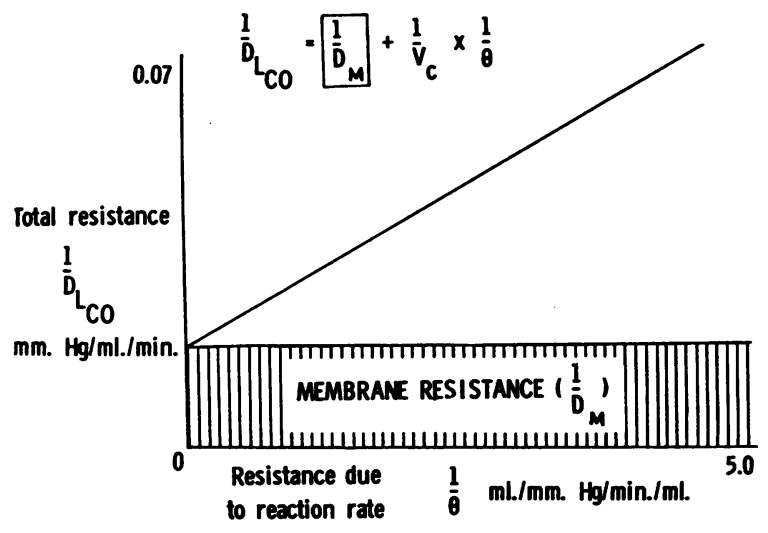

Fig. 1. Graphic Determination of Membrane Diffusing Capacity

A straight line is obtained by plotting the values for $1 /$ D co against appropriate values for $1 / \theta$. The intercept of this line on the vertical axis indicates the resistance due to the pulmonary membrane $\left(1 / D_{\mathbf{x}}\right)$, which is assumed to be constant at any reaction rate.

these measured DLco's are then plotted against appropriate values of $1 / \theta$ a straight line may be drawn connecting these points (Figure 1). At the point where this line intersects the vertical axis $1 / \theta$ is zero and, therefore, the rate of combination of carbon monoxide with oxyhemoglobin is infinitely rapid. Hence, the only resistance to the diffusion of carbon monoxide is that offered by the pulmonary membrane $\left(D_{\mathbf{M}}\right)$ and the value of this intercept is equal to $1 / \mathrm{D}_{\mathbf{u}}$.

If only the triangular area above this intercept is considered (Figure 2) the plotted line is seen to be a graph of blood resistance against reaction rate resistance $(1 / \theta)$. Since blood resistance is the product of $1 / \theta$ and $1 / \mathrm{V}_{0}$, the slope of the line must be $1 / \mathrm{V}_{\mathrm{c}}$, as shown in Figure 2.

$B$. Experimental procedure. Repeated measurements of DLoo at different oxygen tensions are required to compute $V_{\mathbf{c}}$ and $D_{\mathbf{u}}$. The single breath technique of Krogh (4) as standardized by Ogilvie, Forster, Blakemore, and Morton (5) is used because it is simple and rapid. Essentially this technique requires that the subject make a maximal inspiration from his residual volume of a mixture containing 0.3 per cent carbon monoxide, 10 per cent helium and varying concentrations of oxygen and nitrogen, hold his breath for 10 seconds, and then make a maximal rapid expiration, from which, after the dead space of both subject and apparatus is cleared, an "alveolar" sample is taken. To vary the oxygen tensions at which these measurements are made and to estimate the tension of carbon monoxide in equilibrium with blood carboxyhemoglobin, we have modified the apparatus described by Ogilvie and associates (5) to the form shown in Figure 3.

The actual conduct of the experiment is as follows: Bag $L$ is filled with a mixture of approximately 0.3 per cent carbon monoxide, 10 per cent helium and 89.7 per cent oxygen. ${ }^{7}$ The seated subject breathes 100 per cent oxygen from the demand valve $E$ for two minutes to wash most of the nitrogen from his lungs. Tap $F$ is then turned to $\mathrm{J}$ and the subject rebreathes into a 6 liter bag filled with oxygen for four minutes. This constitutes an initial measurement of the carbon monoxide tension in equilibrium with blood carboxyhemoglobin prior to the inspiration of any $\mathrm{CO}$ for the experiment (6). The tap is next turned to $\mathrm{H}$ and a measurement of diffusing capacity is carried out as described above. The "alveolar" sample is collected in evacuated bag D. At the conclusion of this measurement the tap is turned to $E$ once more and the subject breathes oxygen for an additional two minutes. The tap is then turned to $\mathrm{H}$ and the measurement of diffusing capacity repeated. These two measurements constitute a duplicate measurement of DLco at high oxygen tensions. Next the tap is turned to $G$ and the subject breathes room air for two minutes. The measurement of DLco is then repeated twice more with a two minute period on room air between the determinations. Since bag L still contains carbon monoxide-heliumoxygen, duplicate determinations of DLco at alveolar oxygen tensions intermediate between those of preceding and subsequent studies are thus obtained. Bag $\mathrm{L}$ is now evacuated and filled with a mixture of 0.3 per cent carbon monoxide, 10 per cent helium, 20.9 per cent oxygen and 68.8 per cent nitrogen. Two more measurements of diffusing capacity are made with two minutes of room air breathing between them-a duplicate determination of DLco at an oxygen tension close to that of room air. The subject then breathes oxygen for two minutes more and is finally switched to a fresh 6 liter bag (K) filled with oxygen into which he rebreathes for four minutes. This constitutes a final measurement of carbon monoxide tension in equilibrium with blood carboxyhemoglobin. Subsequently the residual volume is determined in duplicate by the closed circuit helium method (7) and venous blood is drawn for determination of hemoglobin by the cyanmethemoglobin method (8).

In experiments to determine the effect of exercise, the subject pedalled for five minutes at a constant rate on a motor-driven bicycle before the first measurement of Dlco, continued to exercise during this determination, during the two minute waiting period and during the duplicate measurement of DLco. He then rested for five minutes and repeated this procedure at the next level of oxygen tension. This exercise was moderate in degree. In Subject C. D., for example, the $\mathrm{O}_{2}$ consumption during the fifth minute of exercise was $770 \mathrm{ml}$. S. T. P. D. The resting residual volume was used in computing DLco.

In experiments to determine the effects of recumbency, the subject lay down just prior to the initial equilibrium sample and remained in this position throughout the study. Residual volume was determined in the recumbent position. In both the exercise and recumbency studies, a resting seated control study was done on the same day; the control and experiment were done in random order.

\footnotetext{
7 Obtained from the Matheson Co., Rutherford, N. J.
} 
C. Gas analysis. Each of the "alveolar" samples to be analyzed is drawn through a dessicating agent by a membrane pump at the rate of $215 \mathrm{ml}$. per minute and then pushed by the pump through, successively, a paramagnetic oxygen analyzer, 8 an infrared carbon dioxide analyzer, ${ }^{9}$ an infrared carbon monoxide analyzer, ${ }^{10}$ a carbon dioxide absorber, a hydrator and finally through a katharometer ${ }^{11}$ for the measurement of helium. Readings of these instruments are made in all cases while the pump is operating and after the sample has been flowing through this system for three to four minutes. Approximately $540 \mathrm{ml}$. of gas is required to clear all the analytical apparatus. The carbon monoxide concentration, as read, is corrected for the carbon dioxide present by the use of a curve obtained by passing known mixtures of carbon dioxide in air through the carbon monoxide analyzer.

The helium measurement requires two corrections: One is necessitated by the fact that the katharometer measures the total thermal conductivity of all gases in the sample, rather than helium specifically. The thermal conductivities of oxygen and nitrogen differ; thus, variations in the concentrations of these two gases alter the total thermal conductivity and hence the observed percentage of helium. For this reason the katharometer has two scales designated "helium in oxygen" and "helium in air." Helium concentration of alveolar samples at high oxygen tensions and at oxygen tensions approximating that of room air can be read directly on their respective scales. Samples having oxygen tensions intermediate between these two are read on the "helium in oxygen" scale and corrected to their true helium concentration by a correction curve derived from the analy-

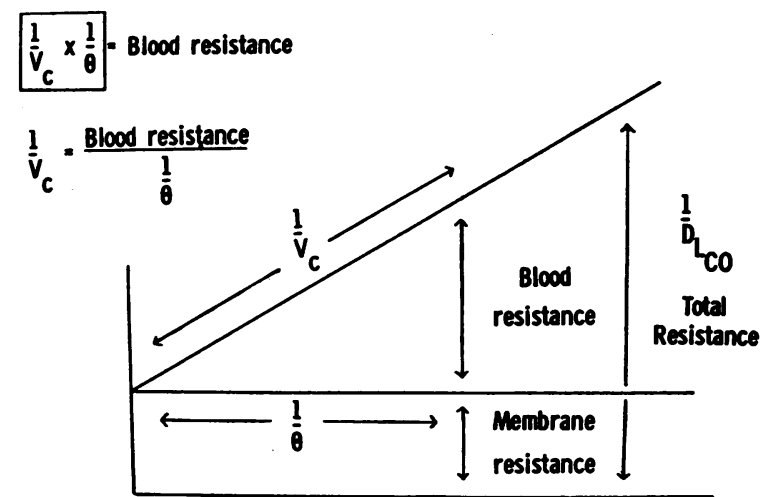

Fig. 2. Graphic Determination of Capillary Volume

The line itself is a plot of blood resistance against reaction rate resistance per $\mathrm{ml}$. of blood $(1 / \theta)$; its slope, therefore, is the reciprocal of capillary volume $\left(1 / \mathrm{V}_{0}\right)$.

\footnotetext{
8 Model E 2, Beckman Instrument Co., Pasadena, Calif.

- Model 16, Liston Becker Division, Beckman Instruments, Stamford, Conn.

10 Model 15, Liston Becker Division, Beckman Instruments, Stamford, Conn.

11 Cambridge Instrument Co., New York, N. Y.
}

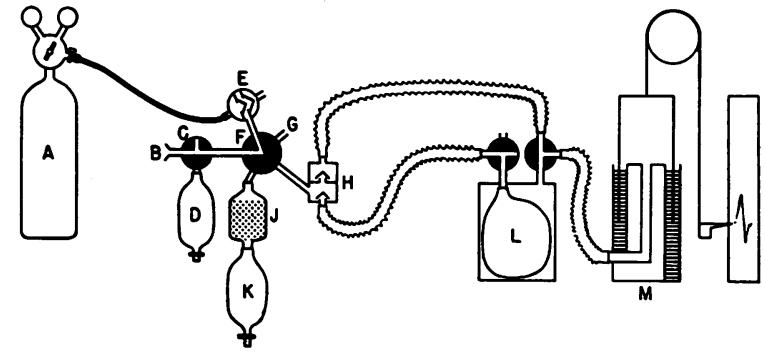

Fig. 3. Schematic Diagram of Apparatus

$A$ is oxygen tank; $B$ is mouthpiece; $C$ is three way tap; $\mathrm{D}$ is 6 liter rubber bag; $\mathrm{E}$ is demand valve; $\mathrm{F}$ is five way tap; $G$ is opening to air; $H$ is flutter valve; $J$ is soda lime canister; $\mathrm{K}$ is 6 liter rubber bag; $\mathrm{L}$ is 25 liter bag-in-box; $M$ is recording spirometer.

sis of known dilutions of a helium-carbon monoxide-oxygen mixture with air. The second correction is for the carbon dioxide absorbed, since this decreases the volume of the sample and thereby increases the observed percentage of helium. This is accomplished by multiplication of the observed helium percentage by $1-\frac{\mathrm{CO}_{2} \%}{100}$.

D. Calculations. The initial $\mathrm{CO}$ concentration in the alveoli is obtained by multiplying the concentration of $\mathrm{CO}$ inspired by the ratio helium expired/helium inspired. From this calculated $\mathrm{CO}$ concentration and from the directly measured expired $\mathrm{CO}$ concentration is subtracted the concentration of $\mathrm{CO}$ in equilibrium with the carboxyhemoglobin of the blood at the capillary $\mathrm{pO}_{2}$ at which Dlco is measured (9). This correction is of greatest magnitude when the alveolar oxygen tension is high, as indicated by the Haldane relationship (1) :

$$
\frac{210 \mathrm{CO} \text { tension }}{\mathrm{O}_{2} \text { tension }}=\frac{\mathrm{COHb} \text { concentration }}{\mathrm{O}_{2} \mathrm{Hb} \text { concentration }} \text {. }
$$

Carboxyhemoglobin is present in significant quantities in the blood of smokers and increases during the experiment in all subjects. During the four minutes of rebreathing into the bag containing oxygen before and after the experiment, the $\mathrm{COHb}$ equilibrates with the gas in the lung-bag system (6). From the tensions of $\mathrm{CO}$ and $\mathrm{O}_{2}$ in the bag, the Haldane relation may be solved for per cent $\mathrm{COHb}$ if there is little reduced $\mathrm{Hb}$. The rise in per cent $\mathrm{COHb}$ between initial and final equilibrations is assumed to occur in equal increments with each determination of DLco. Thus an interpolated value for mean $\mathrm{COHb}$ during each measurement of Dlco is obtained. With this value the Haldane relation can be solved for the $\mathrm{CO}$ tension during each measurement of $\mathrm{DL}_{\mathrm{L} o}$ and this tension (or concentration) may be subtracted from both the initial and final concentrations of $\mathrm{CO}$.

The alveolar volume is the sum of the volume inspired, corrected to S. T. P. D., and the independently measured residual volume. The time of breath holding is measured directly from the respiratory record. Dloo 
is then calculated from the Krogh equation (4) :

$\mathrm{D}_{\text {Lco }}$ (ml. $\mathrm{CO} / \mathrm{mm} . \mathrm{Hg} / \mathrm{min}$.)

$$
\begin{aligned}
=\frac{\text { Alveolar vol. (S. T. P. D.) }}{\text { minutes } \times(\text { barometric pressure }-47)} \\
\quad \times \ln \left[\frac{\text { initial CO conc. in exp. sample }}{\text { final CO conc. in exp. sample }}\right] .
\end{aligned}
$$

Duplicate determinations of DLco at the same oxygen tension which do not agree within 10 per cent of the larger value are discarded.

Values for $1 / \theta$ for the alveolar oxygen tension at which each measurement of $\mathrm{DL}_{\mathrm{co}}$ is made are obtained from the published graphs of Roughton and Forster (3), using a value of 2.5 for the ratio of permeability of the red cell membrane to the permeability of the red cell interior $(\lambda)$. These graphs are constructed for blood having a carbon monoxide (or oxygen) capacity of 20 volumes per cent. Corrections for the hemoglobin concentration $(\mathrm{Hb})$ of the subject are made by multiplying the value of $1 / \theta$ from the graph by the fraction $\frac{20}{\mathrm{Hb} \times 1.34}$, where 1.34 is the oxygen capacity per gram of $\mathrm{Hb}$.

Values for $1 / D_{\text {Loo }}$ are next plotted against corresponding values for $1 / \theta$; the line connecting these points is either drawn by eye, or the best fitting line is computed by the method of least squares. We have used the latter procedure in computing all the data in this study and we have rejected an experiment if the correlation coefficient between $1 / \mathrm{DL}_{\text {co }}$ and $1 / \theta$ is less than 0.95 , indicating that more than 10 per cent of the variation in 1/DLco is not explained by changes in $1 / \theta$. From the slope and intercept of this line $V_{c}$ and $D_{k}$ are obtained as explained above.

\section{RESULTS}

In Table I are listed the age, sex, height, weight, body surface area, vital capacity, $\mathrm{DL}_{\mathrm{Co}}$ while breathing room air, $V_{\mathbf{C}}$ and $D_{\mathbf{M}}$ of 19 normal subjects studied on 23 occasions. In Table II are the correlation coefficients between $V_{C}$ and $D_{M}$ and the parameters height, weight, body surface area, vital capacity and $\mathrm{DL}_{\mathrm{Co}}$ (room air). Except for the correlation coefficient of 0.40 between height and $\mathrm{D}_{\mathbf{M}}$, all these correlation coefficients are significant at the 5 per cent level. In Table III are shown the results of repeated estimates of $V_{C}$ and $D_{M}$ over a period of four months in four subjects. We have included in this table a number of studies in which $V_{\mathbf{C}}$ and $D_{\mathbf{M}}$ were computed from four determinations of $\mathrm{DL}_{\mathrm{CO}}$ at two different oxygen tensions and in which residual volume was assumed to be the same as on some previous study, since such studies might be expected to be more variable than studies performed as described above. The good reproducibility of $\mathrm{V}_{\mathrm{C}}$ (coeffi- cient of variation 8.1 per cent) and the wider variability of $D_{M}$ (coefficient of variation 20.6 per cent) are apparent. Table IV shows the changes produced by moderate exercise in four normal subjects. There is uniformly an increase in $V_{C}$ and $D_{\mathbf{M}}$. Table $V$ shows the changes produced by the recumbent position in four normal subjects. There is a uniform increase in $V_{C}$, but a decrease in $\mathrm{D}_{\mathbf{M}}$.

\section{DISCUSSION}

\section{Accuracy of method}

There is no direct method for measuring $V_{c}$ and $D_{\mathbf{M}}$. The accuracy of the computed values of $V_{\mathbf{C}}$ and $D_{\mathbf{M}}$ reported here must be evaluated $a$ priori from the validity of the assumptions made in these computations. There are three such assumptions : 1) Varying the alveolar $\mathrm{pO}_{2}$ does not change $V_{\mathbf{C}}$ and $\left.D_{\mathbf{M}} ; 2\right) D_{L_{C o}}$ is measurable with accuracy at various $\mathrm{pO}_{2}$ 's; 3 ) accurate values for $\theta$ are available.

Obviously, there is no direct way of proving that alterations in alveolar $\mathrm{pO}_{2}$ do not change $\mathrm{V}_{\mathbf{C}}$ and $\mathrm{D}_{\mathbf{M}}$. Three lines of evidence, however, suggest that such a change does not occur. Cander and Forster (10) have shown that $\mathrm{DL}_{\mathrm{co}}$ at an alveolar $\mathrm{pO}_{2}$ of, for example, $300 \mathrm{~mm}$. $\mathrm{Hg}$ is the same whether this $\mathrm{pO}_{2}$ is attained by breathing oxygen for 10 minutes and then inspiring a mixture containing $\mathrm{CO}$ in room air, or by breathing room air for 10 minutes and then inspiring a $\mathrm{CO}-\mathrm{O}_{2}$ mixture containing no nitrogen. While these data do not exclude an effect of $\mathrm{pO}_{2}$ on $\mathrm{V}_{\mathrm{C}}$ and $\mathrm{D}_{\mathbf{M}}$, the only alternative explanation is that if there is any change it must be very rapid. Dripps and Comroe (11) have reported that breathing 100 per cent $\mathrm{O}_{2}$ increases cardiac output by about 8 per cent in normal subjects. From the data compiled by Forster (12) this much increase in cardiac output should not change $\mathrm{DL}_{\mathbf{C O}}$ (and inferentially $\mathrm{V}_{\mathbf{C}}$ and $\mathrm{D}_{\mathbf{M}}$ ) appreciably. Lastly, the high correlation between $1 / \mathrm{DL}_{\mathrm{Co}}$ and $1 / \theta$ routinely obtained in these experiments suggests that most, if not all, of the change in $\mathrm{DL}_{\mathrm{CO}}$ with changing $\mathrm{pO}_{2}$ is due to changes in $\theta$ and not to changes in $V_{C}$ and $\mathrm{D}_{\mathrm{M}}$.

The validity of the second assumption, that $\mathrm{DL}_{\mathbf{C O}}$ is measurable with accuracy, may be questioned since the various methods for measuring $\mathrm{DL}_{\mathrm{CO}}$ 
TABLE I

PHYSICAL CHARACTERISTICS, VITAL CAPACITY, DLCO $\left(\mathrm{PO}_{2} \mathrm{c} .120\right), \mathrm{V}_{\mathrm{C}}$ AND $\mathrm{D}_{\mathrm{M}}$ OF 19 NORMAL SUBJECTS

\begin{tabular}{|c|c|c|c|c|c|c|c|c|c|}
\hline Subject & Sex & Age & Height & Weight & $\begin{array}{c}\text { Surface } \\
\text { area }\end{array}$ & $\begin{array}{c}\text { Vital } \\
\text { Capacity }\end{array}$ & $D_{L_{C O}}{ }^{*}$ & $\mathbf{D}_{\mathbf{M}}$ & $v_{c}$ \\
\hline & & yrs. & inches & pounds & sq. m. & $\begin{array}{c}\text { ml. } \\
\text { BTPS }\end{array}$ & $\begin{array}{l}\mathrm{mb} / \mathrm{mm} \text {. } \\
\mathrm{Hg} / \mathrm{min} .\end{array}$ & $\begin{array}{l}\mathrm{ml} / \mathrm{mm} \text {, } \\
\mathrm{Hg} / \mathrm{min} \text {. }\end{array}$ & $\mathrm{ml}$ \\
\hline P.F. & $\mathbf{M}$ & 23 & 67.0 & 163 & 1.85 & 4,930 & 30.0 & 107.6 & 65.8 \\
\hline J. J. & $\mathbf{M}$ & 26 & 73.0 & 141 & 1.86 & 4426 & 29.7 & 111.6 & 69.2 \\
\hline E. W. & $\mathbf{M}$ & 24 & 75.0 & 163 & 2.02 & 5,770 & 41.9 & 200.2 & 90.9 \\
\hline R. J. & $\mathbf{M}$ & 27 & 71.8 & 170 & 1.98 & 5200 & 33.9 & 95.9 & 70.0 \\
\hline R.U. & $\mathbf{M}$ & 26 & 71.5 & 182 & 2.04 & 5,700 & 37.3 & 168.5 & 79.4 \\
\hline D. M. & $\mathbf{M}$ & 23 & 71.0 & 165 & 1.94 & 5,210 & 41.6 & 110.4 & 89.8 \\
\hline B.L. & $\mathbf{M}$ & 32 & 71.0 & 155 & 1.90 & 4225 & $\begin{array}{l}28.4 \\
30.0\end{array}$ & $\begin{array}{l}83.8 \\
87.0\end{array}$ & $\begin{array}{l}65.7 \\
72.3\end{array}$ \\
\hline R.K. & $\mathbf{M}$ & 21 & 68.5 & 158 & 1.86 & 5,750 & $\begin{array}{l}34.9 \\
34.5\end{array}$ & $\begin{array}{l}181.3 \\
145.4\end{array}$ & $\begin{array}{l}68.1 \\
66.4\end{array}$ \\
\hline T.L. & $\mathbf{M}$ & 31 & 64.0 & 127 & 1.60 & 3280 & $\begin{array}{l}22.8 \\
25.3\end{array}$ & $\begin{array}{l}48.9 \\
82.0\end{array}$ & $\begin{array}{l}65.1 \\
57.3\end{array}$ \\
\hline C. D. & $\mathbf{M}$ & 22 & 71.0 & 167 & 1.95 & 5,140 & 28.9 & 72.1 & 67.7 \\
\hline G.L. & $\boldsymbol{F}$ & 27 & 63.0 & 121 & 1.56 & 2664 & 23.5 & 67.8 & 67.3 \\
\hline M.W. & $F$ & 24 & 62.0 & 124 & 1.56 & 3605 & 22.8 & 88.1 & 55.3 \\
\hline F.N. & $\boldsymbol{F}$ & 34 & 65.5 & 156 & 1.79 & 3,345 & $\begin{array}{l}21.6 \\
18.9\end{array}$ & $\begin{array}{l}63.5 \\
81.2\end{array}$ & $\begin{array}{l}50.4 \\
40.7\end{array}$ \\
\hline G.H. & $\mathbf{F}$ & 29 & 68.0 & 135 & 1.73 & 3,830 & 30.0 & 103.1 & 74.2 \\
\hline $\mathbf{M} . \mathbf{T}$. & $\mathbf{F}$ & 22 & 62.5 & 115 & 1.52 & 2870 & 23.2 & 54.3 & 68.6 \\
\hline C.Y. & $\mathbf{F}$ & 22 & 63.0 & 105 & 1.46 & 2686 & 18.3 & 114.3 & 38.5 \\
\hline Z.K. & $\mathbf{F}$ & 26 & 62.5 & 108 & 1.48 & 3,126 & 21.99 & 93.5 & 52.3 \\
\hline V.E. & $\mathbf{F}$ & 24 & 62.5 & 110 & 1.49 & 3,970 & 24.4 & 58.6 & 61.7 \\
\hline c.w. & $\mathbf{F}$ & 33 & 66.5 & 130 & 1.68 & 4090 & 18.8 & 38.0 & 59.3 \\
\hline \multicolumn{3}{|c|}{ Mean values } & 66.8 & 143 & 1.76 & 4,149 & 27.9 & 98.1 & 65.0 \\
\hline \multicolumn{3}{|c|}{ Standard deviation } & 4.4 & 22.2 & 0.184 & 3057 & 6.8 & 40.9 & 12.5 \\
\hline
\end{tabular}

* The following abbreviations are used in all tables: DLco = apparent diffusing capacity of the lung for carbon monoxide; $V_{c}=$ capillary blood volume; and $D_{\mathbf{M}}=$ true diffusing capacity of the pulmonary membrane.

give different results. The steady state methods which use either an alveolar sample (13) or the physiological dead space (14) to arrive at a value for alveolar $\mathrm{pCO}$ give lower values than the single breath technique (5). The steady state methods are inaccurate unless ventilation/diffusing capacity ratio is the same for all alveoli (9). Ventilation is uneven to some degree in normal subjects (15).
Further, the alveolar sample technique faces the practical difficulty of deciding what is the correct alveolar sample and the physiological dead space technique requires skilled technical assistance and is quite sensitive to small analytical errors when used in the resting subject (12). The single breath technique will give a result other than the true $\mathrm{DL}_{\text {co }}$ when the ratio diffusing capacity/ 
TABLE II

RELATION OF PHYSICAL CHARACTERISTICS, VITAL CAPACITY, AND $D_{L_{C}}$ TO $V_{c}$ AND $D_{M}$

\begin{tabular}{|l|c|c|}
\hline \multirow{2}{*}{} & \multicolumn{1}{|c|}{ Correlation } & Coefficients \\
\cline { 2 - 3 } & $\mathrm{v}_{\mathrm{c}}$ & $\mathrm{D}_{\mathrm{M}}$ \\
Height & 0.61 & 0.40 \\
Weight & 0.51 & 0.48 \\
Surface Area & 0.61 & 0.54 \\
Vital Capacity & 0.65 & 0.72 \\
$\mathrm{D}_{\text {LO (pO }}$ c. $\left.120 \mathrm{~mm} . \mathrm{Hg}.\right)$ & 0.87 & 0.74 \\
\hline
\end{tabular}

* For explanation of abbreviations, see Table I.

alveolar volume is not the same for all alveoli (9). It is probable that this ratio is uneven in normal subjects (16). However, the technique is rapid and the gas analysis required is easily done by physical means. In our hands it has been possible to complete duplicate determinations of DLoo at three oxygen tensions within one-half hour.

We have used the single breath technique because of this rapidity and simplicity, because steady state methods have no compelling theoretical advantages over single breath method and because steady state methods would measure the diffusing capacity due to capillaries in which blood flow was very slow or even stopped to a much smaller extent than would a single breath method (14). Thus steady state methods might give a better picture of the functioning capillary bed while a single breath method might give a more accurate picture of anatomical state of this bed. In this connection, Roughton and Forster (3) have compared the values of $V_{C}$ and $D_{M}$ obtained by a single

TABLE III

Repeated Determinations of $V_{c}$ and $D_{M}$ in the Same Subject

\begin{tabular}{|c|c|c|c|c|}
\hline Subject & Date & $\begin{array}{c}\mathrm{D}_{\mathrm{LCO}_{\mathrm{co}}{ }^{\dagger}} \\
(\mathrm{p} 02 \mathrm{c} .120 \mathrm{~mm} .) \\
\mathrm{mb} / \mathrm{mm} \cdot \mathrm{Hg}_{\mathrm{g}} / \mathrm{min} .\end{array}$ & $\begin{array}{l}\mathbf{v}_{\mathbf{c}} \\
\mathbf{m l}\end{array}$ & $\frac{D_{M}}{\mathrm{ml} / \mathrm{mm} \mathrm{Hg}_{\mathrm{g}} / \mathrm{min}}$ \\
\hline \multirow[t]{4}{*}{ B.L. } & $7 / 15$ & 29.0 & 65.7 & 83.8 \\
\hline & $8 / 27$ & 30.5 & 72.3 & 87.0 \\
\hline & $10 / 2$ & 32.8 & $70.4 *$ & $108.6 *$ \\
\hline & $11 / 7$ & 29.7 & $66.3 *$ & $82.5 *$ \\
\hline \multirow[t]{5}{*}{ T.L. } & $7 / 17$ & 24.2 & 65.1 & 48.9 \\
\hline & $8 / 26$ & 25.5 & 57.3 & 82.0 \\
\hline & $9 / 25$ & 22.9 & $52.9 *$ & $75.2 *$ \\
\hline & $9 / 26$ & 23.1 & $50.9 *$ & $67.0 *$ \\
\hline & $10 / 7$ & 22.4 & $54.2 *$ & $52.0 *$ \\
\hline \multirow[t]{2}{*}{ R. K. } & $7 / 16$ & 35.0 & 68.1 & 181.3 \\
\hline & $8 / 28$ & 34.5 & 66.4 & 145.4 \\
\hline \multirow[t]{3}{*}{ F.N. } & $7 / 23$ & 21.7 & 50.4 & 63.5 \\
\hline & $8 / 29$ & 18.9 & 40.7 & 81.2 \\
\hline & $10 / 23$ & 17.0 & $52.5 *$ & $33.5 *$ \\
\hline
\end{tabular}

* Based on 4 measurements of Dloo; Residual volume assumed not to vary from previous measurements.

† For explanation of abbreviations, see Table I. 
TABLE IV

EFFECTS OF EXERCISE ON $v_{c}$ AND $D_{M}$

\begin{tabular}{|c|c|c|c|c|}
\hline \multirow{2}{*}{ Subject } & \multicolumn{2}{|c|}{$\mathrm{V}_{\mathrm{c}}{ }^{*}$} & $\mathrm{ml}$ & \multicolumn{2}{c|}{$\mathrm{D}_{\mathrm{M}} \mathrm{ml} / \mathrm{mm} . \mathrm{Hg} / \mathrm{min}}$. \\
\cline { 2 - 5 } & Rest & Exercise & Rest & Exercise \\
\hline T.L. & 57.3 & 62.9 & 82.0 & 137.8 \\
\hline B.L. & 72.3 & 85.3 & 87.0 & 122.5 \\
\hline C.D. & 67.7 & 84.6 & 72.1 & 86.2 \\
\hline C.W. & 59.3 & 70.3 & 38.0 & 54.3 \\
\hline Mean & 64.1 & 75.8 & 69.8 & 100.2 \\
\hline
\end{tabular}

* For explanation of abbreviations, see Table I.

breath method and by a steady state method and found that $V_{C}$ and $D_{M}$ computed from steady state data were, on the average, lower. However, values of $V_{C}$ and $D_{M}$ computed by the two methods overlapped and were not vastly different.

The values of $\theta$ used in these studies were taken from the published data of Roughton and Forster (3) and the probable accuracy of the measurement of $\theta$ has been comprehensively discussed by these authors. In summary, the most important sources of uncertainty in a given value of $\theta$ are the value of $\lambda$ and the value for the pulmonary capillary hematocrit. $\lambda$ is the ratio of permeability of the red cell membrane to permeability of the red cell interior. The smaller its value, the greater the resistance to diffusion offered by the red cell membrane and the less offered by the alveolar-capillary membrane at the same value of $\mathrm{DL}_{\mathbf{c o}}$. Thus, any inaccuracy in the value of $\lambda$ is reflected in the computation of $\mathrm{D}_{\mathbf{M}}$. The computation of $\mathrm{V}_{\mathbf{C}}$, however, is almost independent of the value of $\lambda$. Inaccuracy in the value of the pulmonary capillary hematocrit, on the other hand, affects the computation of $V_{\mathbf{C}}$, but not that of $\mathrm{D}_{\mathbf{M}}$. There is considerable evidence (17) that the pulmonary capillary hematocrit is less than the venous hematocrit. If this is true, the values for $\mathrm{V}_{\mathbf{C}}$ reported here are too low, but the magnitude of such an error is not, at present, known.

To summarize, we feel that our measured values for $\mathrm{DL}_{\mathrm{Co}}$ and the data for $\theta$ that we have used give the correct order of magnitude of the processes they purport to measure, rather than absolute values. More cannot be claimed for the computed values of $\mathrm{V}_{\mathbf{C}}$ and $\mathrm{D}_{\mathbf{M}}$. Accordingly, the greatest usefulness of these computations lies in demonstrating changes in disease states and under altered physiological conditions.

\section{Comparison with other data}

Roughton and Forster (3) have presented data on $V_{C}$ and $D_{M}$ in seven normal subjects whose $\mathrm{DL}_{\mathrm{CO}}$ was measured by a 10 second breath holding technique similar to that used in these studies. Their mean value of $78.7 \mathrm{ml}$. for $\mathrm{V}_{\mathrm{C}}$ does not differ significantly from our mean value of $65.0 \mathrm{ml}$. for 19 subjects while their mean value for $D_{\mathbf{M}}$, $57.6 \mathrm{ml}$. per $\mathrm{mm}$. $\mathrm{Hg}$ per minute, is significantly lower than our value of $98.1 \mathrm{ml}$. per $\mathrm{mm}$. $\mathrm{Hg}$ per minute. There are three differences in technique and computation between the two sets of data: 1) Roughton and Forster computed separate values for $D_{M}$ using reaction rate data at $\lambda$ equals 1.5 and $\lambda$ equals infinity, respectively, and used the average of these two values of $D_{\mathbf{M}}$. We computed $\mathrm{D}_{\mathrm{M}}$ using reaction rate data for $\lambda$ equals 2.5 . Recomputation of our data in the manner of Roughton and Forster makes our average $D_{\mathbf{M}}$ still higher and does not explain the difference. 2) Roughton and Forster subtracted $5 \mathrm{~mm} . \mathrm{Hg}$ from the oxygen tension of their alveolar samples to obtain mean capillary oxygen tension and subsequently appropriate values for $1 / \theta$. If we made this correction our results for $D_{M}$ would be lower and closer to those of Roughton and Forster. The difference thus introduced, however, is rather small. For example, in Subject E. W., the subtraction of $5 \mathrm{~mm}$. $\mathrm{Hg}$ from the oxygen tension of his alveolar samples in obtaining the values for $1 / \theta$ would change $D_{M}$ from 200 to $188 \mathrm{ml}$. per mm.

TABLE V

EFFECTS OF BODY POSITION ON $v_{c}$ AND $D_{M}$

\begin{tabular}{|c|c|c|c|c|}
\hline \multirow{2}{*}{ Subject } & \multicolumn{2}{|c|}{$\mathrm{v}_{\mathrm{c}}{ }^{*}$} & $\mathrm{ml}$. & \multicolumn{2}{c|}{$\mathrm{D}_{\mathrm{M} \mathrm{ml} / \mathrm{mm} . \mathrm{Hg} / \mathrm{min} .}$} \\
\cline { 2 - 5 } Sitting & Recumbent & Sitting & Recumbent \\
\hline B.L. & 57.3 & 87.1 & 82.0 & 60.8 \\
\hline F.N. & 42.3 & 101.2 & 87.0 & 78.8 \\
\hline R.K. & 66.4 & 66.4 & 81.2 & 46.0 \\
\hline Mean & 59.2 & 85.9 & 98.9 & 77.3 \\
\hline
\end{tabular}

* For explanation of abbreviations, see Table $I$. 


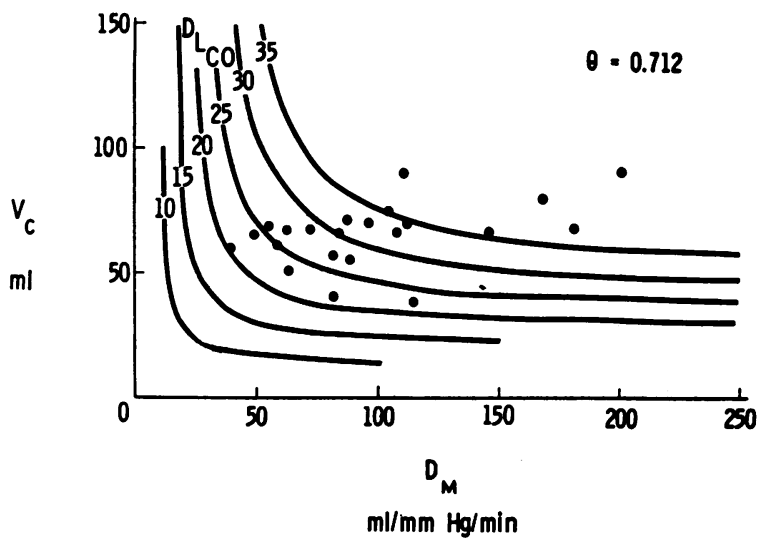

Fig. 4. Relation of Capillary Volume to Membrane Diffusing Capacity

At a fixed value of $D_{\text {co }}$ and $\theta$, the possible values of $V_{c}$ and $D_{\mathbf{m}}$ lie on a rectangular hyperbola. A series of such hyperbolae corresponding to the values of DLco while breathing room air indicated are shown. A value of $0.712 \mathrm{ml}$. per $\mathrm{mm}$. $\mathrm{Hg}$ per $\mathrm{ml}$. blood per minute for $\theta$ corresponding to a $\mathrm{pO}_{2}$ of 120 is used in all cases. Each dot indicates a value for $V_{\mathbf{c}}$ and $D_{\mathbf{x}}$ from Table $\mathrm{I}$.

$\mathrm{Hg}$ per minute. 3) Roughton and Forster analyzed for helium with a mass spectrometer. Our measurement for helium is less specific, since we measured the total thermal conductivity of our samples and interpreted our results as concentration of helium. A systematic error might thus be introduced that would explain the differences between our results and theirs. To explore this point, three "dummy" experiments were done, using a bag containing 2 liters of alveolar air of various oxygen tensions as "lungs." "Alveolar" samples were analyzed and the ratio initial CO concentration in expired sample/final $\mathrm{CO}$ concentration in expired sample was computed as described above. There was no significant difference from the expected ratio of 1.0 and thus there is no evidence of a systematic error in our analyses.

Since differences in technique and computation do not provide an adequate explanation, we feel that the most likely reason for the difference in the two sets of data lies in the mathematical relation of $V_{\mathbf{C}}$ and $D_{\mathbf{M}}$. Rearrangement of Equation 1 to solve for $V_{C}$ yields

$$
\mathrm{V}_{\mathrm{C}}=\mathrm{D}_{\mathrm{M}} \mathrm{DL}_{\mathrm{Co}} / \theta\left(\mathrm{D}_{\mathrm{M}}-\mathrm{DL}_{\mathrm{Co}}\right) \text {. }
$$

The possible values of $V_{C}$ and $D_{M}$ that would satisfy this equation at fixed values of $\mathrm{DL}_{\mathrm{Co}}$ and $\theta$ fall on a rectangular hyperbola (Figure 4). Practically, this means that when a point falls on the horizontal asymptote, as do most of our points for normal subjects, a small change in $V_{C}$ will cause a large change in the value of $D_{M}$. It is apparent that in most cases small increases in our values for $V_{C}$ would have brought our values for $\mathrm{D}_{\mathbf{M}}$ into the range reported by Roughton and Forster. This same relationship between $V_{C}$ and $D_{M}$, we feel, also accounts for the much wider variability of $D_{M}$ as compared with $V_{C}$ which is shown in Table III.

\section{Changes with exercise and position}

An increase in $D_{L}$ with exercise has been observed uniformly by all investigators beginning with Krogh (4). Roughton (18), in 1945, reported that the increase in $\mathrm{D}_{\mathrm{L}}$ was due, in part at least, to an increase in $V_{C}$ on exertion. Our data confirm the increase in $\mathrm{V}_{\mathbf{C}}$ observed by Roughton and show that an increase in $\mathrm{D}_{\mathbf{M}}$ also occurs. Observations of $V_{C}$ and $D_{M}$ on recumbency have not been reported previously, but an increase in $\mathrm{DL}_{\mathrm{Co}}$ has been shown to occur on changing from the sitting to the recumbent position (5). Our data confirm this observation and indicate that an increase in $V_{C}$ accounts for this change. An increase in blood in the lung on recumbency, if not in the capillaries, can be inferred from the wellknown decrease in vital capacity in the lying position, which is partially reversed by inflating cuffs about the extremities prior to recumbency, a procedure that might be expected to prevent blood from pooling in the lungs (19). The decrease in $\mathrm{D}_{\mathbf{M}}$ in our data is not statistically significant because of the great variability in measurements of $\mathrm{D}_{\mathbf{M}}$ noted above, and means only that no significant increase occurred.

The observations reported here are of considerable interest in relation to concepts of the physiology of the pulmonary capillary bed. One concept pictures the capillaries as incapable of dilatation and, consequently, either entirely open or completely closed, with only a small fraction of the capillaries of an alveolus open at any one time. This concept is based on the analysis of physical forces in capillaries by Burton (20) and direct observations of capillaries in the cat lung (21), the frog mesentery (22) and the dog lung 
(23). This may be called the "open-shut" hypothesis. Alternatively, one might picture some capillaries as containing a small volume of blood and having a folded wall. Under appropriate conditions these capillary walls would unfold, increasing capillary volume with an unchanged surface area ("unfolding" hypothesis). Or, some capillaries containing a small volume of blood might be capable of dilatation, increasing both their volume and their surface area ("dilatation" hypothesis). Our data on exercise, in which both $\mathrm{V}_{\mathbf{c}}$ and $\mathrm{D}_{\mathbf{M}}$ increase, could be explained by the "open-shut" hypothesis with the opening up of new capillaries, increasing both the volume of blood and the surface area for diffusion. The "open-shut" hypothesis might explain the results of recumbency only if it were postulated that blood went preferentially to the larger capillaries, thereby increasing the volume of blood in the capillaries, but possibly even decreasing the surface area. The "unfolding" hypothesis might explain the increase in $\mathrm{V}_{\mathbf{C}}$ without change in $D_{M}$ on recumbency, but could not explain the increase in both $V_{C}$ and $D_{M}$ on exercise. The "dilatation" hypothesis would explain our results with exercise but not those on recumbency. The "open-shut" hypothesis of capillary action in the lung, then, might provide a simple explanation of the changes in $V_{C}$ and $D_{M}$ reported here. However, a more complex explanation is not excluded. For example, capillary walls might simply unfold with recumbency, but might be stretched on exercise, increasing their surface area, as Barcroft (24) has suggested, since the functional residual capacity is increased on exercise (25), but is decreased on recumbency (26).

\section{SUM MARY}

1) The pulmonary capillary blood volume $\left(V_{c}\right)$ and the true diffusing capacity of the pulmonary membrane $\left(D_{M}\right)$ have been computed on 23 occasions in 19 normal subjects by the method of Roughton and Forster. The average value for $\mathrm{V}_{\mathbf{C}}$ was $65.0 \mathrm{ml}$; for $\mathrm{D}_{\mathbf{M}}, 98.1 \mathrm{ml}$. per $\mathrm{mm}$. $\mathrm{Hg}$ per minute.

2) In these 19 subjects $V_{C}$ and $D_{M}$ are significantly correlated with height, weight, body surface area, vital capacity and apparent diffusing capacity for $\mathrm{CO}$ while breathing room air.
3) In four subjects $V_{c}$ proved to be stable and reproducible over a period of months while $D_{M}$ was quite variable.

4) $V_{C}$ and $D_{M}$ increased on mild exercise in four subjects.

5) $V_{C}$ increased while $D_{M}$ did not vary significantly when four subjects changed from the seated to the recumbent position.

6) The data for $V_{C}$ and $D_{M}$ reported here probably give the correct order of magnitude of these quantities rather than their absolute values.

7) The average $V_{C}$ in our subjects is similar to that reported elsewhere; our average $D_{\mathbf{M}}$ is significantly higher. This may be due to the mathematical relation of $V_{\mathbf{C}}$ to $D_{M}$ which makes $D_{M}$ highly variable in normal subjects.

8) The hypothesis that capillaries are either shut or completely open appears to be the simplest explanation of our results both on exercise and during recumbency.

\section{ACKNOWLEDGMENT}

The authors wish to acknowledge the assistance of Dr. Robert Davies in facilitating the computations involved in this work.

\section{APPENDIX}

The regression equations for the prediction of $\mathrm{V}_{\mathbf{c}}$ and $D_{\mathbf{m}}$ from the various parameters measured are as follows :

$\mathrm{V}_{\mathrm{c}}(\mathrm{ml})=$.1.74 height (inches) $-51.0 \pm 9.8$

$\mathrm{V}_{\mathrm{c}}(\mathrm{ml})=$.0.285 weight (pounds) $+24.3 \pm 10.7$

$V_{c}(\mathrm{ml})=$.41.1 surface area (sq. M.) $+7.0 \pm 9.8$

$\mathrm{V}_{\mathrm{c}}(\mathrm{ml})=$.0.00717 vital capacity $(\mathrm{ml})+35.3 \pm$.

$\mathrm{V}_{\mathrm{c}}(\mathrm{ml})=.1.59 \mathrm{D}_{\text {Lco }}(\mathrm{ml} . / \mathrm{mm} . \mathrm{Hg} / \mathrm{min})+20.6 \pm$.

$\mathrm{D}_{\mathbf{x}}(\mathrm{ml} . / \mathrm{mm} . \mathrm{Hg} / \mathrm{min}$. $)=3.77$ height (inches) $-153.4 \pm$ 37.5

$\mathrm{D}_{\mathbf{M}}(\mathrm{ml} . / \mathrm{mm} . \mathrm{Hg} / \mathrm{min}$. $)=0.884$ weight (pounds) -27.4 $\pm 35.9$

D $(\mathrm{ml} . / \mathrm{mm} . \mathrm{Hg} / \mathrm{min})=$.120 surface area (sq. M.) $112.4 \pm 34.5$

$\mathrm{D}_{\mathbf{M}}(\mathrm{ml} . / \mathrm{mm} . \mathrm{Hg} / \mathrm{min})=$.0.0279 vital capacity (ml.) $-17.5 \pm 28.4$

$\mathrm{D}_{\mathbf{M}}(\mathrm{ml} . / \mathrm{mm} . \mathrm{Hg} / \mathrm{min})=.4.46 \mathrm{DL}_{\text {co }}(\mathrm{ml} . / \mathrm{mm} . \mathrm{Hg} / \mathrm{min}$. $-26.4 \pm 27.5$

\section{REFERENCES}

1. Roughton, F. J. W. The kinetics of the reaction $\mathrm{CO}+\mathrm{O}_{2} \mathrm{Hb} \rightleftharpoons \mathrm{O}_{2}+\mathrm{COHb}$ in human blood at body temperature. Amer. J. Physiol. 1945, 143, 609.

2. Roughton, F. J. W., Forster, R. E., and Cander, L. Rate at which carbon monoxide replaces oxygen from combination with human hemoglobin in solu- 
tion and in the red cell. J. appl. Physiol. 1957, 11, 269.

3. Roughton, F. J. W., and Forster, R. E. Relative importance of diffusion and chemical reaction rates in determining rate of exchange of gases in the human lung, with special reference to true diffusing capacity of pulmonary membrane and volume of blood in the lung capillaries. J. appl. Physiol. 1957, 11, 290.

4. Krogh, M. The diffusion of gases through the lungs of man. J. Physiol. (Lond.) 1914, 49, 271.

5. Ogilvie, C. M., Forster, R. E., Blakemore, W. S., and Morton, J. W. A standardized breath holding technique for the clinical measurement of the diffusing capacity of the lung for carbon monoxide. J. clin. Invest. 1957, 36, 1.

6. Sjöstrand, T. A method for the determination of carboxyhemoglobin concentrations by analysis of the alveolar air. Acta. physiol. scand. 1948, 16, 201.

7. McMichael, J. A rapid method of determining lung capacity. Clin. Sci. 1939, 4, 167.

8. Evelyn, K. A., and Malloy, H. T. Microdetermination of oxyhemoglobin, methemoglobin, and sulfhemoglobin in a single sample of blood. J. biol. Chem. 1938, 126, 655.

9. Forster, R. E., Fowler, W. S., and Bates, D. V. Considerations on the uptake of carbon monoxide by the lungs. J. clin. Invest. 1954, 33, 1128.

10. Cander, L., and Forster, R. E. Effects of varying alveolar oxygen tension upon pulmonary membrane diffusing capacity and pulmonary capillary blood volume in man. Amer. J. Physiol. 1955, 183, 601.

11. Dripps, R. D., and Comroe, J. H., Jr. The effect of the inhalation of high and low oxygen concentrations on respiration, pulse rate, ballistocardiogram and arterial oxygen saturation (oximeter) of normal individuals. Amer. J. Physiol. 1947, 149, 277.

12. Forster, R. E. Exchange of gases between alveolar air and pulmonary capillary blood: Pulmonary diffusing capacity. Physiol. Rev. 1957, 37, 391.

13. Bates, D. V., Boucot, N. G., and Dormer, A. E. The pulmonary diffusing capacity in normal subjects. J. Physiol. (Lond.) 1955, 129, 237.
14. Filley, G. F., MacIntosh, D. J., and Wright, G. W. Carbon monoxide uptake and pulmonary diffusing capacity in normal subjects at rest and during exercise. J. clin. Invest. 1954, 33, 530.

15. Fowler, W. S. Intrapulmonary distribution of inspired gas. Physiol. Rev. 1952, 32, 1.

16. Forster, R. E., Fowler, W. S., Bates, D. V., and Van Lingen, $B$. The absorption of carbon monoxide by the lungs during breathholding. J. clin. Invest. 1954, 33, 1135.

17. Rapaport, E., Kuida, H., Haynes, F. W., and Dexter, L. Pulmonary red cell and plasma volumes and pulmonary hematocrit in the normal dog. Amer. J. Physiol. 1956, 185, 127.

18. Roughton, F. J. W. The average time spent by the blood in the human lung capillary and it relation to the rates of CO uptake and elimination in man. Amer. J. Physiol. 1945, 143, 621.

19. Dow, $P$. The venous return as a factor affecting the vital capacity. Amer. J. Physiol. 1939, 127, 793.

20. Burton, A. C. On the physical equilibrium of small blood vessels. Amer. J. Physiol. 1951, 164, 319.

21. MacGregor, R. G. Examination of the pulmonary circulation with the microscope. J. Physiol. 1933, $80,65$.

22. Nicol, J., Girling, F., Jerrard, W., Claxton, E. B., and Burton, A. C. Fundamental instability of the small blood vessels and critical closing pressures in vascular beds. Amer. J. Physiol. 1951, 164, 330.

23. Wearn, J. T., Ernstene, A. C., Bromer, A. W., Barr, J. S., German, W. J., and Zschiesche, L. J. The normal behavior of the pulmonary blood vessels with observations on the intermittence of the flow of blood in the arterioles and capillaries. Amer. J. Physiol. 1934, 109, 236.

24. Barcroft, J. Features in the Architecture of Physiological Function. London, Cambridge University Press, 1938.

25. Vezár, F. The regulation of the lung volume and its disturbances. Schweiz. med. Wschr. 1946, 76, 932.

26. Wright, G. W., Place, R., and Princi, F. The physiological effects of pneumoperitoneum upon the respiratory apparatus. Amer. Rev. Tuberc. 1949, 60, 706. 